\title{
A multivariate statistical analysis to determine catch intention in the pink cusk-eel (Genypterus blacodes) longline fishery in southern Chile
}

\author{
Rodrigo Wiff ${ }^{1}$, Guillermo Martin Gonzalez ${ }^{2}$, Francisco Contreras ${ }^{3}$, Marcelo A. San Martín ${ }^{3}$, \\ T. Mariella Canales ${ }^{1}$ \\ ${ }^{1}$ Centre of Applied Ecology and Sustainability, Pontificia Universidad Católica de Chile, C.P. 8331150, \\ Libertador Bernardo O'Higgins 340, Santiago, Chile. \\ (RW) (Corresponding author): E-mail: rodrigo.wiff@gmail.com. ORCID iD: https://orcid.org/0000-0001-7330-4206 \\ (TMC) E-mail: mariella.canales@ gmail.com. ORCID iD: https://orcid.org/0000-0003-3238-5825 \\ ${ }^{2}$ Marine Institute, Rinville, Oranmore, Co. Galway, Ireland. \\ (GMG) E-mail: guillermo.martin@marine.ie. ORCID iD: https://orcid.org/0000-0002-1984-6140 \\ ${ }^{3}$ División de Investigación Pesquera, Instituto de Fomento Pesquero (IFOP), C.P. 2361827, Blanco 839, Valparaíso, Chile. \\ (FC) E-mail: francisco.contreras@ifop.cl. ORCID iD: https://orcid.org/0000-0003-3062-5477 \\ (MASM) E-mail: marcelo.sanmartin@ifop.cl. ORCID iD: https://orcid.org/0000-0003-4284-6322
}

\begin{abstract}
Summary: The definition of catch intention in multispecies fisheries is a key step toward building abundance indexes based on commercial fishing data. Previous analysis to determine catch intention in the pink cusk-eel (Genypterus blacodes) has been based on the idea that fishing tactics remain constant over time (static fishing tactics). We propose a statistical procedure to determine the catch intention of each haul in the industrial longline fisheries in southern Chile, where fishing tactics may vary over time. This procedure is based on principal component analysis and agglomerative hierarchical analysis of the catch composition, and relaxes the assumption of static fishing tactics by selecting a subset of data that is informative for fishing intention (target versus by-catch) every year. Sensitivity analyses were conducted to assess the robustness of variable fishing tactics on the nominal catch rates in pink cusk-eel. Targeted and by-catch time series of nominal catch rates showed a different trend, so determining the catch intention became relevant. Sensitivity analyses showed that trends in targeted catch rates are robust to the variations of fishing tactic per year. We recommend the use of variable fishing tactics for further use in effort standardization and stock assessment of the pink cusk-eel fishery in southern Chile.
\end{abstract}

Keywords: by-catch; CPUE; catch intention; catch composition; fishing tactics; multivariate analysis.

Análisis estadístico multivariado para determinar la intencionalidad de pesca en congrio dorado (Genypterus blacodes) en la pesquería palangrera austral de Chile

Resumen: La definición de intención de captura en pesquerías multi-específicas es un paso fundamental para la determinación de índices de abundancia con datos provenientes de pesca comercial. Los análisis previos para determinar la intencionalidad de captura en congrio dorado (Genypterus blacodes) han estado basados en la idea de que las tácticas de pescas permanecen constante a través del tiempo (táctica de pesca estática). Se propone un procedimiento estadístico para determinar la intencionalidad de captura en cada lance de pesca palangrero industrial en la zona austral de Chile, donde las tácticas de pesca pueden variar a través del tiempo. Este procedimiento está basado en análisis de componentes principales y aglomeración jerárquica de la composición de captura y relaja el supuesto de táctica de pesca estática seleccionando un sub-grupo de datos, los cuales son informativos para la intención de pesca (objetivo versus incidental) cada año. Se realizan análisis de sensibilidad para evaluar la robustez de las tácticas de pesca variables en las tasas de captura nominales de congrio dorado. Series de tiempo de pesca objetivo e incidental muestran diferentes tendencias, y por lo tanto, la determinación de táctica de pesca se hace relevante en esta pesquería. El análisis de sensibilidad muestra que las tendencias en las tasas de captura objetivo son robustas a las variaciones de tácticas de pesca por año. Se recomienda el uso de tácticas de pesca variable para su posterior uso en estandarización de esfuerzo y evaluación de stock en la pesquería de congrio dorado en la zona austral de Chile.

Palabras claves: pesca incidental; CPUE; intención de pesca; composición de captura; tácticas de pesca; análisis multivariado.

Citation/Como citar este artículo: Wiff R., Martin Gonzalez G., Contreras F., San Martín M.A., Canales T.M. 2020. A multivariate statistical analysis to determine catch intention in the pink cusk-eel (Genypterus blacodes) longline fishery in southern Chile. Sci. Mar. 84(1): 17-26. https://doi.org/10.3989/scimar.04953.30A

Editor: J. Salat.

Received: May 17, 2019. Accepted: January 21, 2020. Published: February 11, 2020.

Copyright: ( $) 2020$ CSIC. This is an open-access article distributed under the terms of the Creative Commons Attribution 4.0 International (CC BY 4.0) License. 


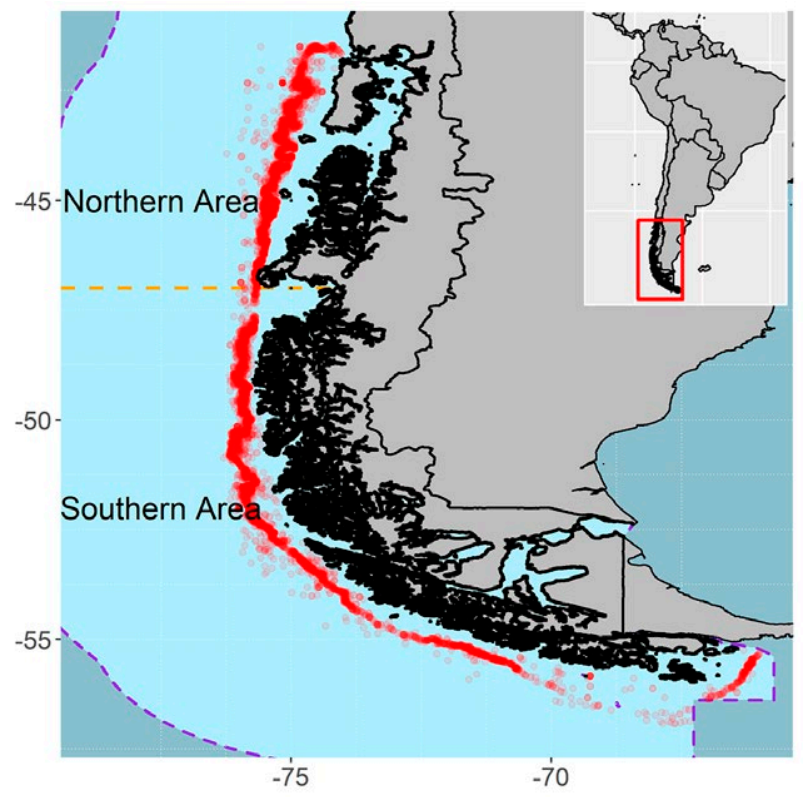

Fig. 1. - Map of the study area indicating the fishing areas. Red dots are the hauls with presence of pink cusk-eel in longline industrial fishery.

\section{INTRODUCTION}

Pink cusk-eel (Genypterus blacodes) is one of the most important fish harvested off southern Chile in terms of landing volumes, local consumption levels and fishing history. However, in Chile it is considered as a secondary target species, or by-catch, by comparison with other fish species of higher economic value in international markets, such as southern hake (Merluccius australis) or Patagonian toothfish (Dissostichus elegi- noides). First official landing records of pink cusk-eel in Chile date back to industrial trawlers operating in the Chilean austral zone in $1978\left(41^{\circ} 28.6^{\prime} \mathrm{S}-57^{\circ} 00^{\prime} \mathrm{S}\right.$, Fig. 1). Today, pink cusk-eel is harvested in Chile by multiple fleets that also target several other species, and the fishery is divided into two fleet components, industrial and artisanal. The industrial fleet is comprised of trawlers and longline vessels operating exclusively in the open sea, whereas the artisanal fishery is comprised of longline vessels operating in the fjords and inner channels of the austral zone.

The pink cusk-eel fishery is one of the few in Chile that has been monitored since its beginnings in the early 1970s, when the intention to catch this species was low. During the 1980s, the fishing intention started to rise to significant levels as a result of intense fishing pressure (Fig. 2). Subsequently, in 1992, management authorities classified the pink cusk-eel fishery as a "fully exploited regime". This particular management regime is established in the Chilean General Law on Fishing and Aquaculture and, in general, empowers the management authority to allocate an annual quota (Wiff et al. 2016). In this context, since 1992, this fishery has been managed on the basis of total allowable catches, which requires estimates of population abundance. These estimates have been usually computed using catch-at-age stock assessment models. These models are calibrated using abundances indexes obtained from catch rates resulting from commercial fishing operations. Until 2004, the conceptual population model only considered a single stock unit for the entire austral zone, from $41^{\circ} 28.6^{\prime}$ to $57^{\circ} 00^{\prime} \mathrm{S}$. However, several differences in life history attributes and demographic characteristics suggested a differentiation of two independent stocks of pink cusk-eel, one in the northern area $\left(41^{\circ} 28.6^{\prime} \mathrm{S}-47^{\circ} 00^{\prime} \mathrm{S}\right)$

\section{Northern Area}

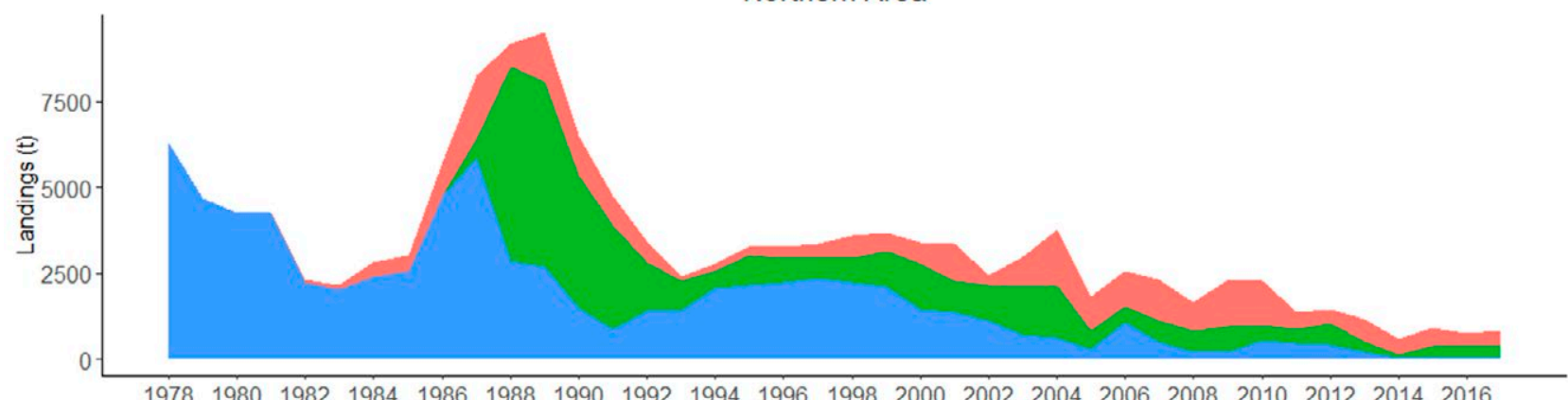

Southern Area

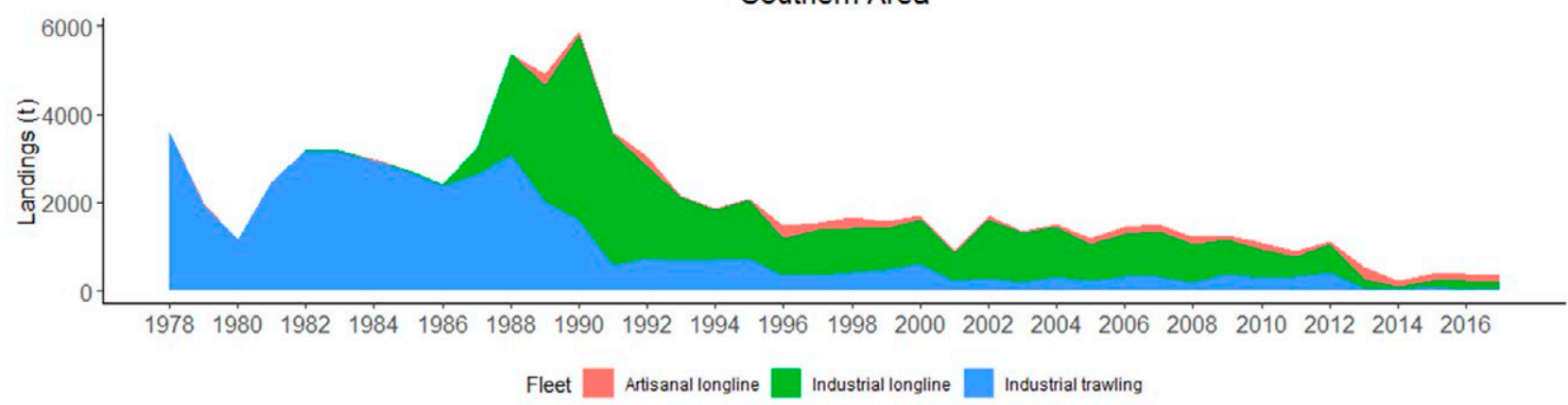

Fig. 2. - Stacked plots of historical landing in pink cusk-eel by fleets and fishing areas. 
and one in the southern area $\left(47^{\circ} 00^{\prime}-57^{\circ} 00^{\prime} \mathrm{S}\right.$, Fig. 1) (Wiff et al. 2007, 2011, Baker et al. 2014). Originally, the stock assessment was calibrated using standardized catch per unit of effort (CPUE) obtained from industrial trawlers (catch per trawled time) and longliners (catch per soaked hooks). International peer-review conducted with respect to this fishery in 2013 recommended the use of abundance indexes coming solely from longliners (Contreras et al. 2015), so further analysis of the catch intention presented in this paper will only consider this fleet. Although landings for trawlers are important in volume (Fig. 2), they have been historically catching pink cusk-eel as by-catch in trawlable fishing grounds different to those fished by longliners (Wiff et al. 2019). In addition, the artisanal fisheries that target this species only operate inside the fjords and inner channels of the austral zone, where industrial operations are banned.

Catch composition of the Chilean demersal southern fishery (CDF) is based on several species, which are caught simultaneously in the same area (JuradoMolina et al. 2016). However, there are only three or four species which account for large part of the catch percentage and its economic value. Historically, the main by-catch species encountered when targeting pink cusk-eel is southern hake, and in smaller proportions Patagonian grenadier (Macruronus magellanicus), tadpole codling (Salilota australis) and skates (Zearaja chilenis and Dipturus trachyderma). These species are also targeted by the artisanal and industrial fisheries, and the changes in target intention depend on multiple factors such as season, management decisions or market conditions (Céspedes et al. 2015). Results from onboard scientific observers on the CDF show different assemblage compositions depending on the targeted species encountered in each haul (Bernal et al. 2013), so determining the level of target or by-catch species of a particular fleet is not straightforward in this fishery. This situation challenges the assessment of the relationship between total effort displayed by a specific fleet and total mortality resulting from the application of this effort (Pelletier and Ferraris 2000). When the information comes exclusively from fishing logbooks, catch intention may only be inferred from the resulting catch composition (Biseau 1998). Catch intention is usually determined by assigning each haul or fishing trip to a particular fishing tactic. We define fishing tactics as the target decision made by a skipper before each fishing operation, and it has been reported as the main factor influencing the effort standardization in pink cusk-eel (Wiff et al. 2006).

Since 2005, a multivariate analysis of the catch composition has been applied to the pink cusk-eel fishing logbooks to assign fishing tactics to every haul and thus characterize each one in terms of fishing intentionality (Wiff et al. 2006). This early approach consisted in determining fishing tactics of the hauls that recorded pink cusk-eel using the method described in Wiff et al. (2008). Using such a method, groups with similar characteristics of catch composition were assigned, and these groups can be seen as part of fishing tactics (Wiff et al. 2008). The main assumption of the method in Wiff et al. (2008) is that the fishing tactic remains constant across years in terms of species composition and the number of tactics that can be allowed each year (known as a "static fishing tactic"). This can result in assumptions that are difficult to meet in the pink cusk-eel fishery because, given the extensive database, changes in management and fishing strategies can lead to changes in the number of fishing tactics found across years. The general definition of a static fishing tactic comes from an association of species that does not change over time (e.g. Alemany and Alvarez 2003, Wiff et al. 2008), or it is defined as a "snapshot" of the species association in one particular year (Davie and Lordan 2011). Applying a static fishing tactic allows the use of the entire database, because each haul or fishing trip can be assigned to a particular fishing tactic, which can be comparable over time. This allows fishing tactics to be used as categorical variables in effort standardization in order to remove all non-temporal factors affecting catch rates, including fishing tactics. This fishing standardization process is only feasible because fishing tactics are treated as a categorical variable and are constant and comparable across years. We propose a new procedure for identifying fishing tactics across years, which relaxes the assumption of static fishing tactics by selecting a subset of data informing on fishing intention every year (target versus by-catch) that can then be used for further effort standardization analyses. Following Stephens and MacCall (2004), we refer to this process as "sub-setting", because it involves filtering out a subset of information on fishing targeting each year using multivariate statistics. In practice, sub-setting is often based on ad hoc and subjective decision rules (Stephens and MacCall 2004), and in this paper we offer a procedure based on multivariate statistics of catch composition which is reproducible and amenable for further sensitivity analyses. The definition of fishing tactic is a step toward effort standardization via generalized models. Therefore, the main aim of this paper is to propose a procedure for determining catch intention in which fishing tactics may vary across years, using catch composition and sub-setting the data into different targeting intentions.

\section{MATERIALS AND METHODS}

\section{Data}

The data from each haul were derived from logbooks collected through the CDF monitoring programme which includes operational details and catch composition information from the industrial longline fishery between 1988 and 2017.

Data pre-processing included deleting records lacking effort information (e.g. number of hooks per line) and maintaining only those hauls recorded in the CDF area $\left(41^{\circ} 28.6^{\prime} \mathrm{S}-47^{\circ} 00^{\prime} \mathrm{S}\right)$ and at longitudes greater than or equal to $66^{\circ} \mathrm{W}$ to represent the area where fishing for pink cusk-eel is likely (Céspedes et al. 2015). An exploratory analysis indicated that the Patagonian toothfish diverges from the operational characteristics of the rest of the species, being found at different depths and in different spatial areas. It is well known that the Patago- 
Table 1. - Summary of operational characteristics of the longline industrial fishery in southern Chile. North and South refer to the fishing areas, catch indicates the total reported catch of pink cusk-eel. Target refers to the percentage of the total catch per year intending to target pink cusk-eel (Scenario 3, variable fishing tactics).

\begin{tabular}{|c|c|c|c|c|c|c|c|c|c|c|}
\hline \multirow{2}{*}{ Year } & \multicolumn{2}{|c|}{ Mean Vessel Length (m) } & \multicolumn{2}{|c|}{ Fishing Hauls (n) } & \multicolumn{2}{|c|}{ Soaked Hooks (n) } & \multicolumn{2}{|c|}{ Catch $(\mathrm{t})$} & \multicolumn{2}{|c|}{ Target (percentage) } \\
\hline & North & South & North & South & North & South & North & South & North & South \\
\hline 1988 & 44.5 & 41.5 & 101 & 67 & 1508716 & 1123680 & 773 & 469 & 76 & 64 \\
\hline 1989 & 38.2 & 47.5 & 769 & 505 & 11481169 & 7322860 & 2936 & 1567 & 47 & 81 \\
\hline 1990 & 36.1 & 45.5 & 948 & 903 & 13146115 & 12492533 & 1750 & 1467 & 89 & 89 \\
\hline 1991 & 31.6 & 42.8 & 1130 & 689 & 15713505 & 10059726 & 1860 & 713 & 70 & 60 \\
\hline 1992 & 29.9 & 42.3 & 492 & 668 & 5897290 & 7210976 & 901 & 728 & 87 & 69 \\
\hline 1993 & 30.8 & 44.9 & 217 & 298 & 2581888 & 4226928 & 373 & 231 & 58 & 27 \\
\hline 1994 & 32.7 & 45.4 & 105 & 439 & 1119417 & 6674240 & 185 & 547 & 87 & 63 \\
\hline 1995 & 45.2 & 45.2 & 86 & 578 & 1336560 & 8782835 & 504 & 1934 & 80 & 15 \\
\hline 1996 & 43.1 & 45.1 & 111 & 431 & 1716280 & 6976480 & 519 & 438 & 53 & 68 \\
\hline 1997 & 34.4 & 45.0 & 123 & 338 & 1310407 & 5308188 & 536 & 471 & 56 & 44 \\
\hline 1998 & 31.9 & 45.6 & 172 & 493 & 883640 & 7877012 & 423 & 502 & 72 & 74 \\
\hline 1999 & 33.7 & 46.2 & 299 & 424 & 1936120 & 6800420 & 729 & 455 & 78 & 48 \\
\hline 2000 & 32.2 & 46.0 & 399 & 410 & 2189744 & 7286564 & 1055 & 531 & 84 & 51 \\
\hline 2001 & 33.9 & 45.8 & 389 & 588 & 2428433 & 9173283 & 793 & 664 & 78 & 70 \\
\hline 2002 & 39.9 & 45.8 & 343 & 470 & 3724100 & 7548340 & 800 & 924 & 64 & 86 \\
\hline 2003 & 41.3 & 45.6 & 307 & 713 & 3721730 & 10887684 & 1039 & 790 & 93 & 73 \\
\hline 2004 & 42.1 & 45.5 & 400 & 734 & 5203704 & 11496714 & 1194 & 981 & 79 & 92 \\
\hline 2005 & 45.1 & 46.1 & 255 & 798 & 3939452 & 12116304 & 740 & 806 & 71 & 83 \\
\hline 2006 & 44.8 & 46.3 & 210 & 859 & 3382470 & 14627258 & 633 & 851 & 87 & 71 \\
\hline 2007 & 45.0 & 45.8 & 173 & 838 & 3143294 & 13973932 & 463 & 798 & 93 & 79 \\
\hline 2008 & 45.4 & 46.0 & 163 & 634 & 2807100 & 10163684 & 484 & 510 & 79 & 63 \\
\hline 2009 & 43.9 & 47.1 & 158 & 749 & 2621046 & 11984822 & 461 & 562 & 79 & 79 \\
\hline 2010 & 44.3 & 46.2 & 136 & 569 & 2252960 & 10022812 & 308 & 376 & 82 & 79 \\
\hline 2011 & 46.1 & 46.0 & 61 & 374 & 1106544 & 6379194 & 104 & 221 & 82 & 59 \\
\hline 2012 & 47.4 & 47.3 & 155 & 452 & 2852317 & 7710980 & 529 & 174 & 80 & 46 \\
\hline 2013 & 48.4 & 48.0 & 148 & 327 & 1621502 & 5134932 & 222 & 111 & 54 & 41 \\
\hline 2014 & & 47.7 & & 135 & & 1845170 & & 67 & & 64 \\
\hline 2015 & 48.9 & 47.6 & 89 & 350 & 880436 & 4543369 & 213 & 131 & 78 & 60 \\
\hline 2016 & 49.3 & 47.6 & 89 & 385 & 867600 & 5861049 & 221 & 170 & 65 & 58 \\
\hline 2017 & 49.2 & 47.2 & 107 & 313 & 1184360 & 4046262 & 291 & 152 & 84 & 58 \\
\hline
\end{tabular}

nian toothfish constitutes a specific fishery in the CDF, so hauls including over $50 \%$ of the catch in weight of this species were excluded from further analysis. We considered that a proportion of Patagonian toothfish of less than $50 \%$ is likely to correspond to those caught as a by-catch of the pink cusk-eel fishery. Likewise, only hauls conducted at depths shallower than $600 \mathrm{~m}$ were retained for further analyses, given the historical knowledge on pink cusk-eel fishing grounds (Céspedes et al. 2015). Additionally, non-identified species and those that were encountered in less than $0.5 \%$ of the total number of hauls were removed. Finally, weight per species was transformed to the corresponding proportion in each haul. Following this pre-processing stage, a total of 23674 hauls from 55 different fishing vessels were retained for further analysis (81438 from the northern area and 15531 from the southern area), with a total of 24 species recorded (Table 1).

\section{Statistical analysis}

The analyses were conducted independently for each of the 30 years and fishing areas (northern/southern). The first stage consisted in identifying the year $(j)$ in area $(a)$. Subsequently, for each year $j$ in area $a$, a principal component analysis (PCA) was conducted on a file containing the contribution (in weight) of each species to the total catch per haul. The final file used contained 23674 rows (hauls) and 24 columns (species recorded, including pink cusk-eel). The PCA analysis allowed us to synthesize the information related to the variables (species) into a few orthogonal components. Preliminary analyses suggested that the retention of the first six orthogonal components in the PCA was optimum each year, and those components when grouped account for over $99 \%$ of the total variance. A second step consisted in applying agglomerative hierarchical analysis (AHA) to the PCA scores retained to assess the different fishing tactics in the pink cusk-eel fishery. AHA was based on successive pairwise element agglomerations (Ward 1963) and the Euclidean distance was used as a similarity measurement. We recovered the original information related to the fishing hauls for each year $j$ and subsequently identified each cluster that represented a fishing tactic (Wiff et al. 2008). The average proportion of species in each fishing tactic (cluster) was computed.

Three scenarios for sensitivity analysis were used. In Scenario 1 (named the "fixed fishing tactic"), we fixed the number of fishing tactics (clusters) that can be retained each year between one (meaning not distinguishing between fishing tactics) and five each year. In Scenario 2 (named "variable fishing tactics") the number of fishing tactics was variable across years and the number was chosen according to the number of species found that accounts for $95 \%$ of the catch in weight. Considering that Scenarios 1 and 2 involve a data sub-setting, we then defined a subset of data consisting of catches of pink cusk-eel either targeted or by-catch, allowing those datasets to be worked out separately for further analysis. Scenario 3 was based on the use of a static fishing tactic (see Alemany and Alvarez 2003, Wiff et al. 2008), in which the number of fishing tactics were fixed across years [in this study we allow three aggregations given previous knowledge on the fisheries in Wiff et al. (2006)]. Scenario 3 is referred to hereafter as the "static fishing tactic". 

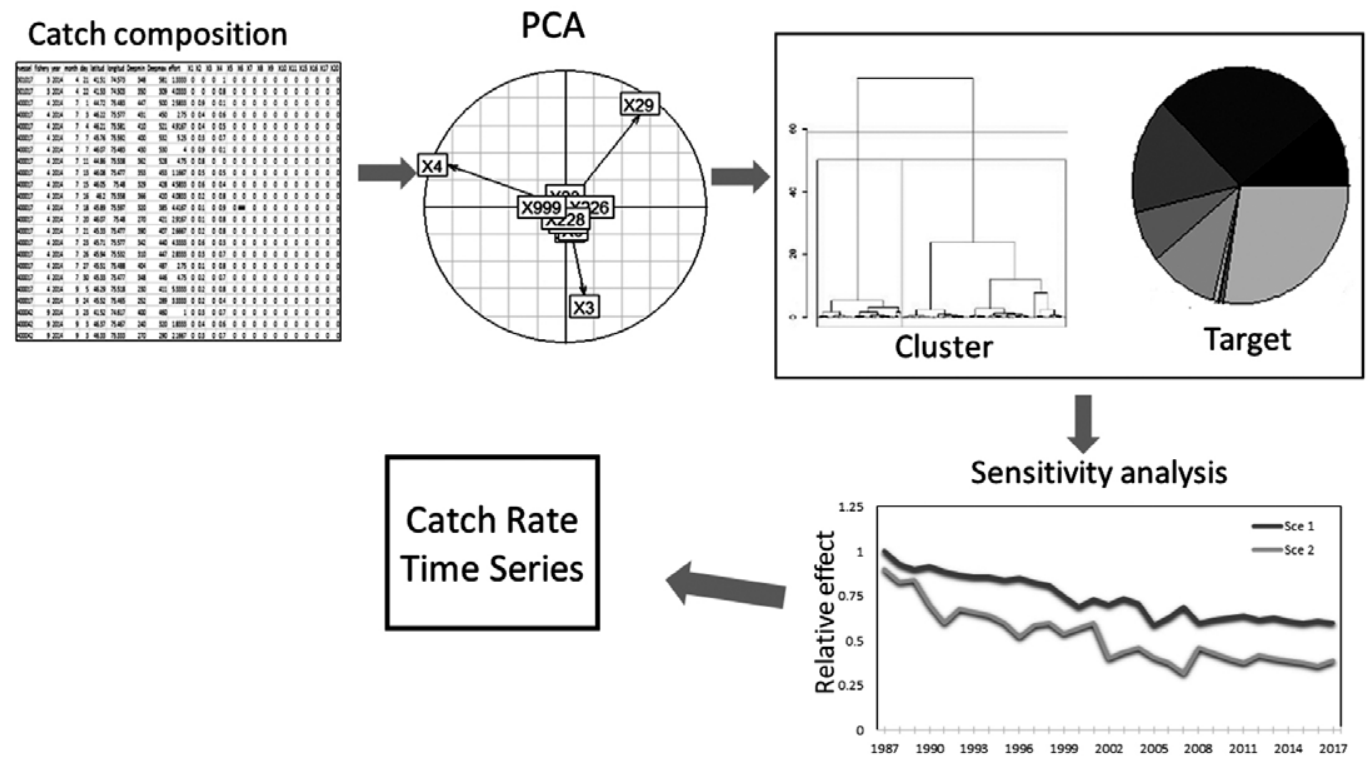

Fig. 3. - Schematic diagram of the statistical analysis implemented to assign catch intention in the longline fishery of pink cusk-eel.

Figure 3 shows a schematic diagram of the statistical analysis implemented to assign catch intention. All analyses were conducted in R-project (R Core Team 2017), and the codes can be made available upon request.

\section{RESULTS}

A summary of the characteristics of the fishing operations of the industrial longline fisheries harvesting pink cusk-eel in the southern area off Chile can be found in Table 1. The Chilean Fishing Law defines all vessels over $18 \mathrm{~m}$ of length as "industrial". Prior to 2003, in the northern area, the average length of vessels operating on pink cusk-eel was less than $40 \mathrm{~m}$ (except in 1995 and 1996). After 2003, vessels in this area increased their length, reaching almost $50 \mathrm{~m}$ in recent years. In the southern area, the mean length of vessels has remained more stable over time, at around 45-47 m. Fishing effort, measured in terms of number of hauls or soaked hooks, reached the peak in 1991 in both areas. Afterwards, the fishing effort decreased over time in the northern zone, but in the southern area effort peaked again in 2001. In 2017, effort was

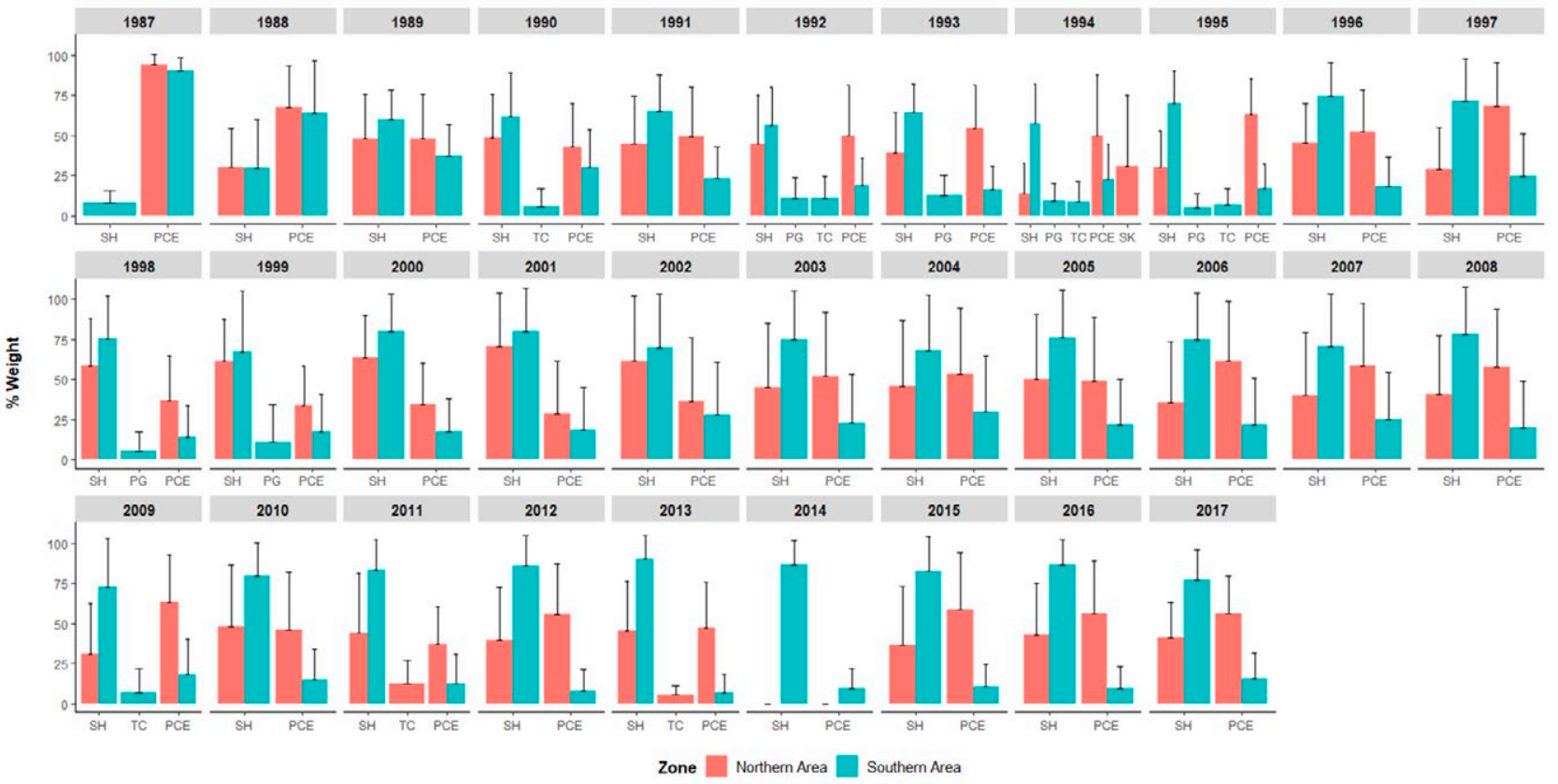

Fig. 4. - Annual average proportions of the main species (\%weight $>5 \%)$ caught in the pink cusk-eel fishery. Northern and southern refers to stock in the austral zone. SH, southern hake; PG, Patagonian grenadier; TC, tadpole codling; PCE, pink cusk-eel; SK, generic skates. Vertical lines indicate the standard deviation. 


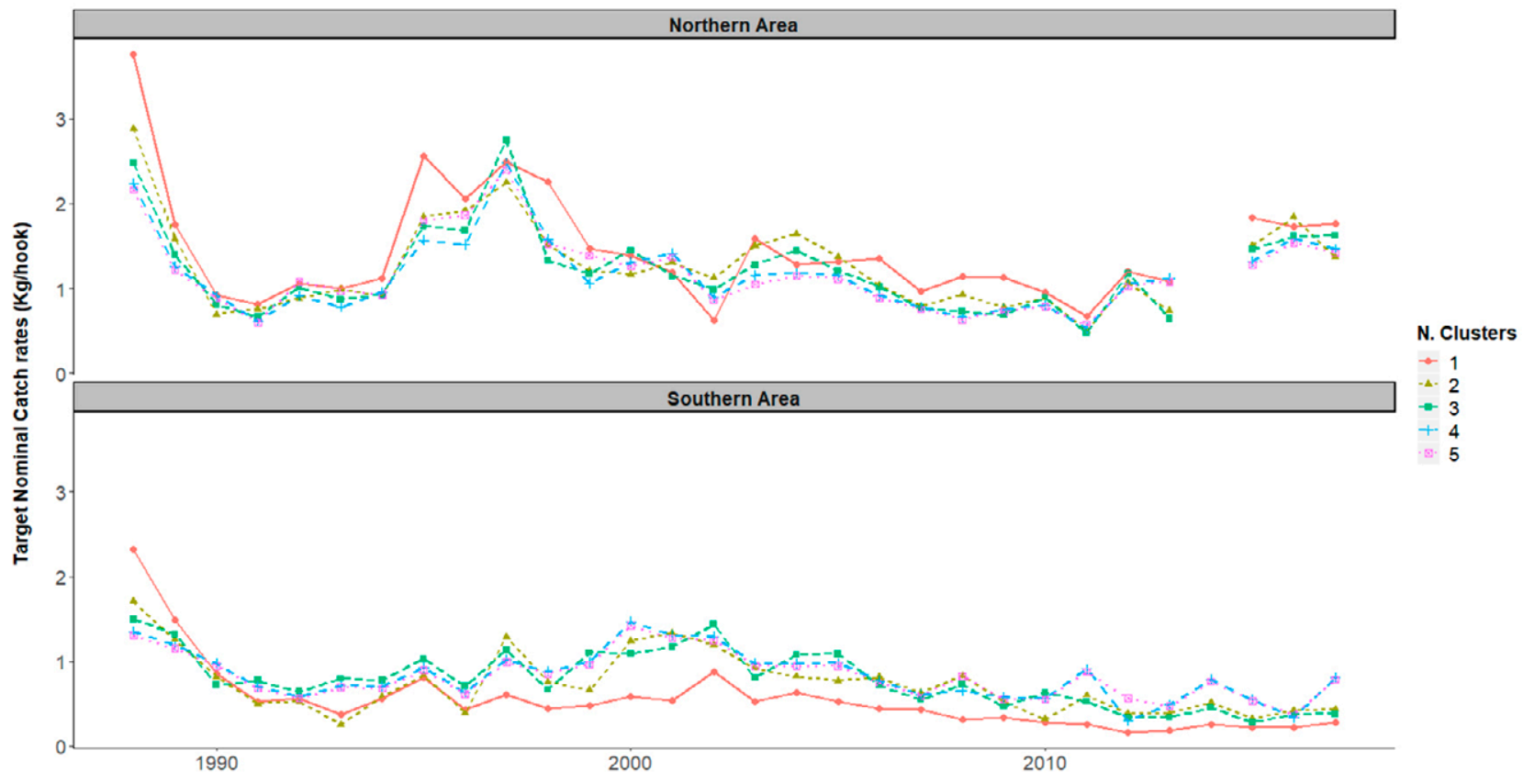

Fig. 5. - Nominal catch rates of pink cusk-eel caught as targeted and depending on a fixed tactic (Scenario 1) used across years. Time series were standardized to their mean.

relatively low in both fishing areas, but higher in the southern area (Table 1). Most of the high catches in both areas were reported prior to the implementation of fishing effort regulations in 1992. In the southern area, the highest catch was recorded in 1995, but only $15 \%$ of that total catch targeted pink cusk-eel (Table 1).

The main species encountered as by-catch when pink cusk-eel was targeted were southern hake (Merluccius australis) and, in smaller proportions, Patagonian grenadier (Macruronus magellanicus), tadpole codling (Salilota australis) and skates (Zearaja chilenis and
Dipturus trachyderma). The proportion of pink cusk-eel that determined target intention changed across years and fishing areas (Fig. 4). The northern zone showed a higher average proportion of targeted pink cusk-eel than the southern zone. The proportion of pink cusk-eel defining the target cluster changed across years and fishing areas, showing high variability. The proportion of southern hake also varied across years and areas but was usually higher in the southern area (Fig. 4).

Figure 5 shows the results of Scenario 1 (fixed fishing tactics) to assess the effect of using a fixed num-

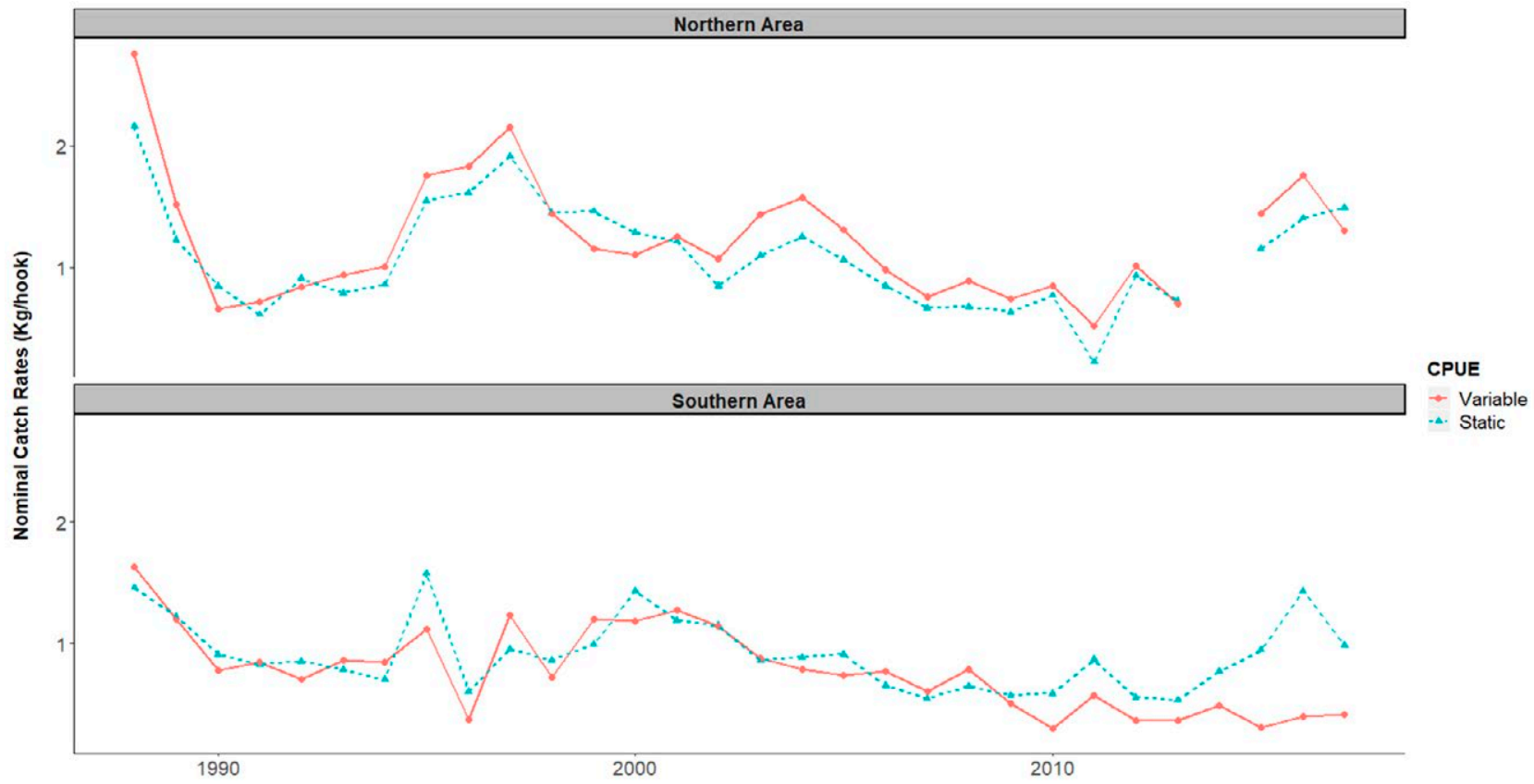

Fig. 6. - Nominal catch rates in the clusters in which pink cusk-eel is caught as targeted using either static or variable fishing tactics (number of clusters) per year. 


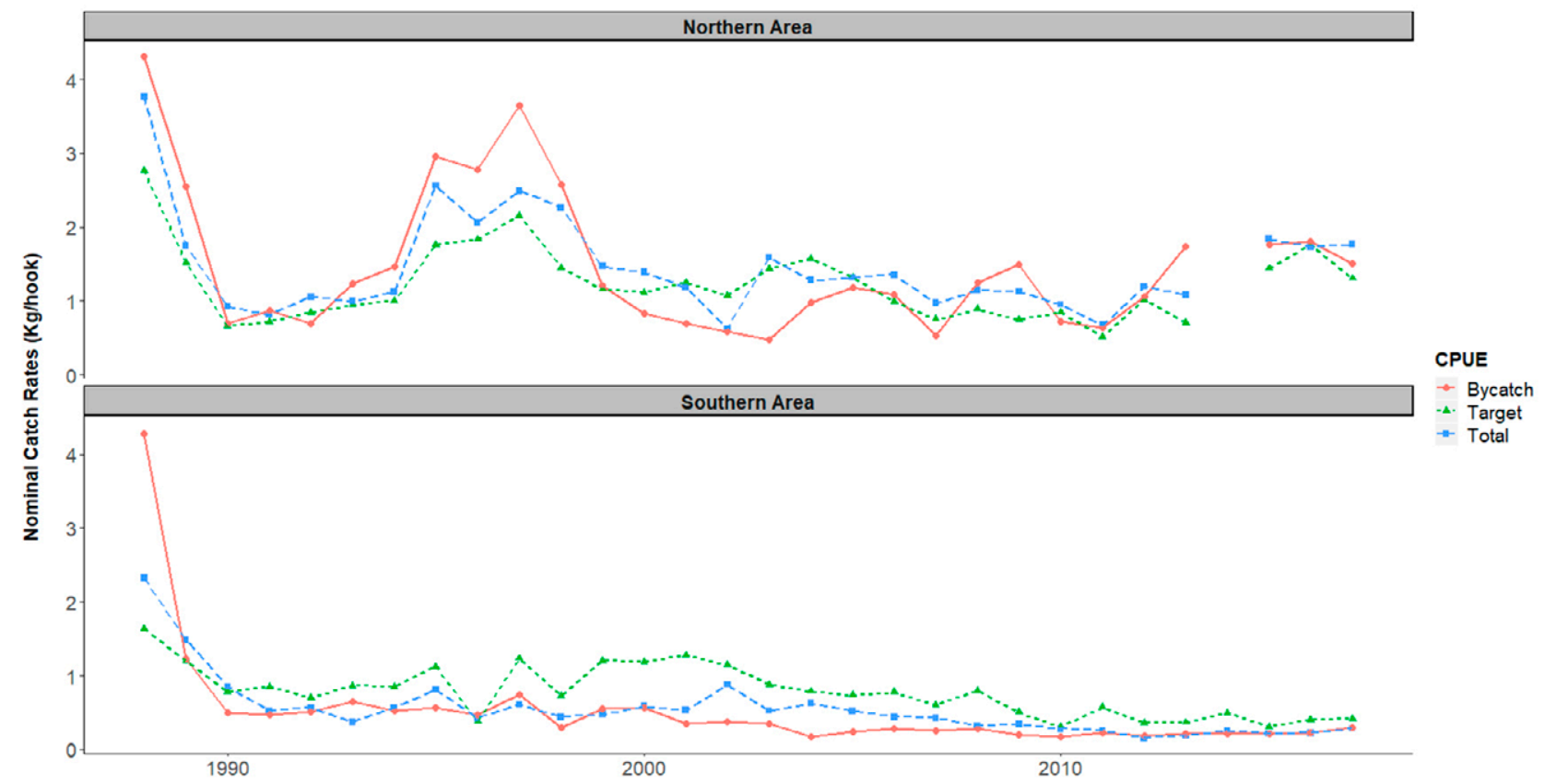

Fig. 7. - Nominal catch rates in the clusters in which pink cusk-eel is caught as targeted (variable clustering per year), total (without fishing tactic) or by-catch. Scenario 2, variable fishing tactics.

ber of fishing tactics across years. It is noted that the lack of data during 2014 in the northern zone is due to the low number of fishing operations conducted that year because of the low quota allocated. This analysis shows differences in time series of nominal catch rates of pink cusk-eel using more than one fishing tactic $(>2$ clusters) compared with no distinction between fishing tactics ( 1 cluster). The differences in using 2 or 5 clusters make negligible changes in the catch rate trends. When a single fishing tactic was allowed across years, the time series of nominal catch rates was lower, as a result of combining fishing hauls targeting pink cuskeel with high catch rates with ones with low catch rates in which pink cusk-eel was caught as by-catch. As a result of the latter, changes in the nominal catch rates across time were less pronounced because by-catch "buffers" or "masks" the underlying trend of catch rates when pink cusk-eel is targeted. In addition, the effect of using a fishing tactic ( $>2$ clusters) was more marked in the southern zone, where trends in CPUE changed dramatically (Fig. 5). This result shows that fishing tactics are important in determining the CPUE in both areas of the pink cusk-eel fishery in Chile.

Figure 6 shows the comparison between Scenario 2 (variable fishing tactics) and Scenario 3 (a static fishing tactic). In both fishing areas, the use of variables versus static fishing tactics produced changes in the times series trends of nominal catch rates. However, this variation of marked effects in the southern area, in addition to the incorporation of variable fishing tactics, produced a rapid decrease in catch rates following the year 2000 in comparison with the use of a static tactic across years (Fig. 6).

Figure 7 shows the comparison of nominal CPUE time series for Scenario 2, variable fishing tactics across the year. Since this scenario included data sub- setting, we compared the total database (all hauls with pink cusk-eel and no distinguishing fishing tactics) and by-catch CPUE (clusters targeting southern hake with pink cusk-eel on the records). Time series of nominal catch rates for pink cusk-eel categorized as target, bycatch and total showed differences in trend and scale in both fishing areas (Fig. 7). As explained above, the time series of total catch rates was a mix of by-catch and targeted hauls and therefore showed an intermediate level of catch rates. On the other hand, the time series by-catch showed low catch rates as a result of pink cusk-eel being usually caught in low proportions. Likewise, time series of targeted hauls usually correlated with a high proportion of pink cusk-eel on the records (see Table 1), so this time series showed the highest catch rates. In this context, the use of variable fishing tactics caused target time series of target catch rates to show a faster decline in comparison with catch rates obtained from total data (especially after 2000). This means that the fishing tactic must have had an effect on catch rates with particular importance following the year 2000 in both fishing areas. These changes in catch rates will affect fishing effort standardization and, subsequently, the use of catch rates as index of abundance.

\section{DISCUSSION}

In this study we have presented a new procedure for identifying fishing tactics across years by allowing the number of fishing tactics to emerge from the catch composition of hauls. This procedure is based on the idea of data sub-setting to categorize each haul in targeted operations or as by-catch. Our results indicate variable proportions of pink cusk-eel in the target cluster across years and fishing areas, therefore suggesting that vari- 
ables with fishing tactic (more than two clusters) lead to significant differences in the trend of nominal catch rates for pink cusk-eel in the northern and southern fishing areas. The new procedure seemed robust to the variations and numbers of fishing tactics per years, indicating that the assumption of a static fishing tactic used in the previous analysis of pink cusk-eel catch rates was not appropriate. The new procedure leads to a better representation of the changes in abundance of the pink cusk-eel in the CDF that accounts for changes in fishery management.

Determining fishing tactics led to different trends in nominal catch rates of pink cusk-eel in both areas. These differences in trends across tactics became more marked after the year 2000, as a response to changes in fisheries management. In 2001, the Chilean fisheries law introduced the concept of individual transferable quotas (ITQs). This led to an uneven distribution of effort, in which the bulk of fishing operations were concentrated in the northern area and during the earliest part of the year, and continued steadily until the quota was completed (Baker et al. 2014). ITQs allowed fishers greater flexibility with relation to when and where they fish. This changed the nature of the exploitation of pink cusk-eel, and fishing operations for the species were performed later in the year and as a secondary target to southern hake.

Sensitivity analyses of Scenario 1 show that trends in nominal catch rate time series display slight variations when 2 to 4 fishing tactics (clusters) are used in both fishing areas. However, the use of a single fishing tactic shows a different trend in the nominal catch rates compared with using two or more fishing tactics in both fishing areas. Likewise, the use of five fishing tactics, although, similar to using two to four, still shows an up-and-down behaviour over time. When only one cluster is used, all hauls containing pink cusk-eel are treated equally in terms of targeting, so changes in the nominal catch rate trends are less pronounced in comparison with when fishing tactics are allowed to emerge (using two or more clusters). On the other hand, small scale variations in nominal catch rates when five clusters are used are produced by rare or occasional species found in particular years in the longline southern fishery off Chile. Therefore, the analysis of fixed fishing tactics indicates that choosing two to four clusters across years is robust for detecting changes in catch rate trends of pink cusk-eel in both fishing areas. This analysis is then refined in Scenario 2 by allowing the number of clusters to change across years (variable fishing tactics) and be dependent on the number of main species caught. The analysis shows that the nominal catch rate trend is smoother, which can be interpreted as a better representation of an index of abundance for this species. In demersal species with a relatively long lifespan such as pink cusk-eel, we would expect smooth changes in abundance over time as a result of a stock comprised of several age classes acting as a buffer for changes in recruitment and having control on fishing mortality via catch quotas. Therefore, we recommend Scenario 2, the use of an adaptive (variable) number of clusters across years as the best time series of nominal catch rates for further analysis towards developing an abundance index in a fishing effort standardization.

Target fishing tactics showed a faster decrease following the year 2000 in both fishing areas, and subsequently an increase in nominal catch rates from the year 2011 only in the northern area. This is particularly important for determining population status and recommending conservation measures for pink cusk-eel. The stock assessment of this species in Chile is based only on fishery-dependent data, in which abundance estimates are highly influenced by a standardized CPUE from industrial longline fishing operations (Contreras et al. 2015). Thus, biomass time series and therefore exploitation status are mostly determined by the trend in catch rates of industrial longliners. This is especially important in the last years of the time series, considering that this trend will determine the management actions to be enforced. Failing to account for fishing tactics will produce a time series of relative abundance that does not exhibit major trends over time. This is caused by the effects of hauls with pink cuskeel as by-catch because these hauls mask and distort the depletion experienced in real fishing grounds. This process is known as "hyperstability", when abundance decreases faster than catch rates (Harley et al. 2001). Hyperstability in catch rates can be the main cause for the delay in detecting biomass depletion, especially in fisheries such as that of pink cusk-eel, in which the only reliable abundance index comes from commercial fishing operations (Wiff et al. 2006). Following the year 2011, the use of fishing tactics in the northern area will predict a faster recovery of the population in comparison with using the total amount of data (Scenario 2). This can also be explained by the use of hauls with pink cusk-eel as by-catch, which distort or mask the changes in abundance.

The main desirable characteristics of using catch rates as the abundance index are (i) a homogeneous catchability across time; (ii) a uniformly distributed fishing effort in space; and (iii) a homogeneous catch intention across fishing hauls. These requirements are particularly difficult to achieve in multispecies fisheries, where catch rates show high variations depending on a variety of factors (Fall et al. 2006, Palmer et al. 2009, Thorson et al. 2012). Despite these drawbacks, the relative abundance index based on catch per unit effort is commonly used in stock assessment. In this context, bias in an abundance index could give rise to bias in the stock assessment due to either underestimating or overestimating the stock abundance, in addition to leading to deficiencies in management decisions. To avoid or reduce any biases, the best information available is required. Therefore, the approach presented in this paper allows uncertainty to be reduced and contributes a refined subset of key data to further standardize catch and effort rates as abundance indexes in the stock assessment.

Analysis of catch intention based on catch composition has been considered as a promising method for filtering effort (Alemany and Alvarez 2003, GarciaRodriguez 2003, Wiff et al. 2008). We suggest a meth- 
od for determining the catch intention, which produces subsets of data according to the status of targeting or by-catch in each particular haul. This allows us to assess variations in catch intention over time, which makes sense in long-history fisheries such as that of the pink cusk-eel in Chile. The common method for assessing fishing intention using static aggregations across fishing hauls is a particular challenge to accomplish in the standardization of CPUE in multispecies fisheries, in which fishing tactics vary over time as a result of conservation measurements or effort restrictions. In recent years, some techniques have been developed based on the basic idea that compositional data on catch or effort from multispecies fisheries can be used as surrogates for the unobserved variable (i.e. the fishing tactics) (Okamura et al. 2018), or multivariate techniques can be used together with the incorporation of expert (ad hoc) decision-making rules (Davie and Lordan 2011). However, these methods do not account for the interaction between time (years) and the unobserved (target intention) variable. As an alternative to these models, approaches for data sub-setting based on logistic regression for multispecies presence-absence have been presented (Stephens and MacCall 2004). Our approach also considered sub-setting data, but it is based on multivariate analysis of catch composition and automatic detection of the number of tactics allowed in each year. The main drawback of this sub-setting technique is information loss in the data required as the subset, which may lead to a low precision of abundance indexes (Okamura et al. 2018). However, unbiased mean trends in abundances indexes are important in terms of the stock assessment, and the precision arising from the standardization process is rarely incorporated in the assessment. Therefore, the method for determining catch intention will depend on knowledge of the fisheries and data availability. In fisheries with a long history of management (such as the North Sea) a multivariable analysis with ad hoc expert knowledge seems to be useful (Davie and Lordan 2011). On the other hand, where covariates of catch rates (e.g. operational, spatial and environmental ones) are also available, a method for subrogates of unobserved fishing tactics seems appropriate. When large amounts of catch rate data are available and fishing tactics seem to interact over time (year to year), a method for sub-setting can be recommended.

Since 2011, Chile has made important efforts to assess all catch compositions, including discards, via fisheries monitoring using onboard scientific observers. Preliminary results of discard monitoring in trawlers and longliners indicate that the percentage of pink cusk-eel, even in targeted fishing hauls, is low with a high proportion of other by-catch species (Bernal et al. 2013, 2017, 2019). This recent and intensive monitoring of by-catch species in CDF, has allowed the detection of spatio-temporal changes on the catch intention of the main target species. In addition, analysis of catch rates in pink cusk-eel can also be improved by addressing the spatial component of the fishing effort. The large extension of these fisheries, together with the sedentary behaviour of this species (Baker et al. 2014) leads us to believe that fishing is exploiting relatively small and well-defined fishing grounds. Thus, a refinement of the procedure proposed should be applied to this historical fishing ground which will contribute to modelling the extra noise produced by changes in areas across time and using catch rates as an index of abundance, thus avoiding changes in catchability caused by changes in fishing grounds across time.

We propose an analysis framework that relaxes two of the main assumptions of the static fishing tactic presented in Wiff et al. (2008). First, the assumption of only a static fishing tactic is relaxed by allowing a dependence of fishing tactic on time. Second, fishing tactics can also vary in number in each year, allowing a better, smoother trend in catch rates of pink cusk-eel. The analysis then allows the identification of a subset of target or by-catch databases. This constitutes the first step towards the analysis of catch rates as abundance index, and we therefore recommended data sub-setting prior to effort standardization in any fishery where the target intention changes across years. Particularly in pink cusk-eel, the use of raw data with no differences in fishing tactics leads to catch rates that can be misleading as abundance indexes, therefore resulting in a biased estimation of abundance and management advice. Therefore, we recommend considering variable fishing tactics (Scenario 2) to improve the assessment of the abundance index in the pink cusk-eel fishery and other fisheries with similar conditions and thereby improve stock assessments and management decisions.

\section{ACKNOWLEDGEMENTS}

We are sincerely grateful to two anonymous reviewers, whose comments and suggestions greatly improved an early version of this manuscript. The authors are grateful to the onboard scientific observers of the discard programme developed by IFOP, to Claudio Gatica for his helpful comments on an earlier version of this manuscript and to Aurora Guerrero (Under-Secretariat of Fisheries) for her logistical advice. G. Martin Gonzalez is grateful to IFOP for granting a short-term research visitor position during which part of the analysis was conducted. R. Wiff and T.M. Canales were funded by the CONICYT PIA/BASAL FB0002 Project. This research was funded by the "Fondo de Investigación Pesquera y de Acuicultura" project, number FIPA 2017-46.

\section{REFERENCES}

Alemany F., Alvarez F. 2003. Determination of effective fishing effort on hake Merluccius merluccius in a Mediterranean trawl fishery. Sci. Mar. 67: 491-499. https://doi.org/10.3989/scimar.2003.67n4491

Baker L.L., Wiff R., Quiroz J.C., et al. 2014. Reproductive ecology of the female pink cusk-eel (Genypterus blacodes): evaluating differences between fishery management zones in the Chilean austral zone. Environ. Biol. Fish. 97: 1083-1093. https://doi.org/10.1007/s10641-013-0199-2

Bernal C., González A., Vargas R., et al. 2013. Asesoría Integral para la Toma de Decisiones en Pesca y Acuicultura. Observadores Científicos, 2012. Actividad 3: Asesoría de Carácter Transversal. Informe Final. Subsecretaría de Pesca y Acuicultura. 339 pp. (Request a copy at: http://www.subpesca.cl). 
Bernal C., San Martín M.A., Bravo C., et al. 2017. Programa de Investigación del Descarte y Captura de Pesca Incidental, 2016-2017. Programa de Monitoreo y Evaluación de los Planes de Reducción del Descarte. Informe final Sección Pesquerías Sur Australes. IFOP: 214 pp. (Request a copy at: http://www. subpesca.cl).

Bernal C., San Martín M.A., Escobar V., et al. 2019. Programa de Investigación del Descarte y Captura de Pesca Incidental 2017 2018. Programa de Monitoreo y Evaluación de los Planes de Reducción del Descarte y Captura de Pesca Incidental 2017 2018. Informe final Sección II. IFOP: 230 pp. (Request a copy at: http://www.subpesca.cl).

Biseau A. 1998. Definition of a directed fishing effort in a mixedspecies trawl fishery, and its impact on stock assessment. Aquat. Living Resour. 11: 119-136. https://doi.org/10.1016/S0990-7440(98)80109-5

Céspedes R., Chong L., San Juan R., et al. 2015. Convenio de desempeño 2014. Programa de Seguimiento de las Pesquerías Demersales y Aguas Profundas, Sección V: Recursos de Aguas Profundas, 2014. Informe Final. Subsecretaría de Economía y EMT. (Request a copy at: http://www.subpesca.cl).

Contreras F., Chong L., Céspedes R. 2015. Estatus y posibilidades de explotación sustentables de los principales recursos pesqueros nacionales 2016, Congrio Dorado, 2016. Informe de Estatus, Subsecretaria de Economía y EMT. (Request a copy at: http:// www.subpesca.cl).

Davie S., Lordan C. 2011. Definition, dynamics and stability of métiers in the Irish otter trawl fleet. Fish. Res. 111: 145-158. https://doi.org/10.1016/j.fishres.2011.07.005

Fall M., Samba A., Lalo F. 2006. Fishing tactics and strategies in coastal demersal trawling fisheries in Senegal. Aquat. Living Resour. 19: 307-316. https://doi.org/10.1051/alr:2007001

Garcia-Rodriguez M. 2003. Characterization and standardization of a red shrimp, Aristeus antennatus (Risso, 1816), fishery off the Alicante gulf (SE Spain). Sci. Mar. 67: 63-74. https://doi.org/10.3989/scimar.2003.67n163

Harley S.J., Myers R.A., Dunn A. 2001. Is catch-per-unit-effort proportional to abundance? Can. J. Fish. Aquat. Sci. 58: 1760-1772. https://doi.org/10.1139/f01-112

Jurado-Molina J., Gatica C., Arancibia H., et al. 2016. A Multispecies Virtual Population Analysis for the Southern Chilean Demersal Fishery. Mar. Coast. Fish. 8: 350-360. https://doi.org/10.1080/19425120.2016.1167796

Okamura H., Morita S.H., Funamoto T., et al. 2018. Target-based catch-per-unit-effort standardization in multispecies fisheries. Can. J. Fish. Aquat. Sci. 75: 452-463. https://doi.org/10.1139/cjfas-2016-0460
Palmer M., Quetglas A., Guijarro B., et al. 2009. Performance of artificial neural networks and discriminant analysis in predicting fishing tactics from multispecific fisheries. Can. J. Fish. Aquat. Sci. 66: 224-237. https://doi.org/10.1139/F08-208

Pelletier D., Ferraris J. 2000. A Multivariate approach for defining fishing tactics from commercial catch and effort data. Can. J. Fish. Aquat. Sci. 57: 51-65. https://doi.org/10.1139/f99-176

R Core Team. 2017. R: A language and environment for statistical computing. R Foundation for Statistical Computing, Vienna, Austria. https://www.R-project.org/

Stephens A., MacCall A. 2004. A multispecies approach to subsetting log- book data for purposes of estimating CPUE. Fish. Res. 70: 299-310. https://doi.org/10.1016/j.fishres.2004.08.009

Thorson J.T., Stewart I.J., Punt A.E. 2012. Development and application of an agent-based model to evaluate methods for estimating relative abundance indices for shoaling fish such as Pacific rockfish (Sebastes spp.). ICES J. Mar. Sci. 69: 635-647. https://doi.org/10.1093/icesjms/fss003

Ward J. 1963. Hierarchical grouping to optimise an objective function. J. Am. Statist. Assoc. 58: 236-244. https://doi.org/10.1080/01621459.1963.10500845

Wiff R., Quiroz J.C., Ojeda V. 2006. Investigación y CTP de Congrio Dorado 2006. Informe Final. IFOP-SUBPESCA. (Request a copy at: http://www.subpesca.cl).

Wiff R., Ojeda V., Quiroz J.C. 2007. Age and growth in pink cuskeel (Genypterus blacodes) off the Chilean austral zone: Evaluating differences between management fishing zones. J. Appl. Ichthyol. 23: 270-272. https://doi.org/10.1111/j.1439-0426.2007.00854.x

Wiff R., Quiroz J.C., Tascheri R., et al. 2008. Effect of fishing tactics on the standardization of cardinalfish (Epigonus crassicaudus) catch rates in the demersal multiespecies fishery off central Chile. Cienc. Mar. 34: 143-154 https://doi.org/10.7773/cm.v34i2.1196

Wiff R., Quiroz J.C., Ojeda V., et al. 2011. Estimation of natural mortality and uncertainty in pink cusk-eel (Genypterus blacodes Schneider, 1801) in southern Chile. Lat. Amer. J. Aquat. Res. 39: 316-326.

Wiff R., Quiroz J.C., Neira S., et al. 2016. Chilean Fishing law, maximum sustainable yield and the stock-recruitment relationship. Lat. Am. J. Aquat. Res. 44: 380-391.

Wiff R., Queirolo D., Ahumada M., et al. 2019. Construcción de indicadores de abundancia de congrio dorado en la pesquería demersal austral (PDA). Technical report FIPA 2017-46. 